\title{
Economy and Environmental Analysis of Various Tower Foundation Types
}

\author{
Yaqiong Liu ${ }^{1, *}$, Wanfu $\mathrm{Cui}^{1}$,Cheng Xin ${ }^{1}$, and Kailin $\mathrm{Ji}^{1}$ \\ ${ }^{1}$ Technical Economic Center, State Grid Economic and Technological Research Institute CO., LTD, Beijing, China
}

\begin{abstract}
Due to increasing environmental problems, more attention of environmental protections is attracted by infrastructure projects. Electricity as an important infrastructure, the environmental analysis of the projects will be a vital part in future preliminary preparation of power grid constructions. Meantime, the economy of the projects is the cornerstone of the company. Therefore, the balance of the economy and environmental costs is significant for executions of the projects. Thus, the paper is focused on discovering the relationship of economy and environmental analysis of various tower foundation types. The environmental analysis contains environmental damage costs, carbon dioxide emissions from construction materials and machinery during construction. Then, the costs and tons of carbon dioxide emissions are compared in same conditions. The conclusion of the paper is that the overall trend is that economy and total carbon emissions show a large positive correlation, and there is no large correlation between economy and environmental damage costs.
\end{abstract}

\section{Introduction}

The 2020 China Central Economic Work Conference determined that carbon peaking and carbon neutrality are two important tasks in 2021. China have set a target for carbon dioxide emissions and strive to reach a peak by 2030, and strive to achieve carbon neutrality by 2060 .

In order to implement the spirit of the Fifth Plenary Session of the 19th Central Committee of the Communist Party of China and the Central Economic Work Conference, the Chinese Academy of Engineering has established a major consulting project "China's Carbon Peak and Carbon Neutralization Strategy and Path Research". The project has set up eight topics, of which the third is about electricity industry, "Research on the implementation path of carbon neutrality in the power industry". Therefore, the carbon dioxide emission in electricity industry is a major factor in the following development.

The carbon dioxide emissions of electricity are mainly concentrated in power grid construction. As the continuous development of infrastructure construction, there are new technology, new process, new equipment and new material showed up, the carbon emissions of them are supposed to be determined.

With the continuous development of new technologies in infrastructure construction, engineering construction methods are becoming more diversified, and tower foundation types are also becoming more diversified. Environmental analysis has become an important factor to be considered in the promotion and application of new technologies.

Meanwhile, the economy is still the vital factor for healthy operation of a company. Therefore, in order to show a comprehensive view of different tower foundation types, the economy is considered with the environmental analysis. In the process of selecting the basic type of the tower, effectively balancing the economy and environmental protection of the optional basic type, and choosing the comprehensive optimal plan is an important way to realize the economic construction and sustainable development of power grid projects.

By establishing the quantitative model of the economic and environmental protection of the tower foundation, this paper carries out quantitative calculation of the economic and environmental protection of the optional foundation, and investigates the relationship between economy and environmental protections, so as to provide support for the investment decision of overhead line engineering.

\section{Methodology}

\subsection{Selection of foundation types}

After sorting out the topography, geological conditions and foundation types, according to the type proportions in "State Grid Corporation of China General Design Scheme Project Cost Level Analysis and Research Report (2018 Edition)", combined with expert opinions, retain representative flat, mountain topography and ordinary soil, hard soil, pine sandstone, rocks and muddy water geological conditions, all feasible foundation types under various geological conditions are taken as the research objects.

\footnotetext{
* Corresponding author: lyaqiongp117@sina.com
} 


\subsection{Measurement of economy of foundation types}

The paper takes the amount of basic ontology cost as an economic indicator. In the specific terrain and geological conditions, for each feasible basic type, select a typical case to determine the amount of engineering, according to the pre-rules and quota to prepare the ontological cost estimates.

\subsubsection{Standards of economy calculation}

Economic research mainly adopts the method of preparing budget estimates to estimate its construction cost.

(1) Project division and fee collection standards are in accordance with the "Regulations on the Preparation and Calculation of Power Grid Project Construction Budgets" (2013 Edition) issued by the National Energy Administration and the People's Republic of China Electric Power Industry Standards DL/T 54672013, DL/T 5471 5472-2013, DL/T 5479-2013.

(2) The quota adopts the 2013 version of the Electric Power Construction Project Quota Valuation Table.

(3) The price of installation materials is based on the "Comprehensive Budget Price of Installation Materials for Electric Power Construction Projects" (2013 tax-except version) and the "Individual Budget Price of Installation Materials for Electric Power Construction Projects" (the 2013 tax-exempt version) issued by the China Electricity Council.

\subsubsection{Boundary conditions of economy calculation}

The cost data calculated in this study is based on 7 boundary conditions. The boundary conditions and their selection are based on the following

(1) The topography calculated this time is divided into flat land and mountainous land.

(2) This calculation only considers two voltage levels of $220 \mathrm{kV}$ and $500 \mathrm{kV}$.

(3) The estimated geology includes ordinary soil, hard soil, pine sandstone, rock, and muddy water.

(4) Under flat terrain, the commonly used conventional foundation types are digging pile foundation, inclined column foundation, straight column foundation, digging foundation, cast-in-place pile foundation, rock anchor foundation, and new foundation types are PHC pipe pile foundation, fabricated foundation, etc. In mountainous terrain, the commonly used conventional foundation types are digging pile foundation, digging foundation, and rock bolt foundation.

(5) This calculation distinguishes different voltage levels, tower types (straight line or tensile tower), and the number of circuits based on the basic force.

(6) In this calculation, mechanized construction is considered.

(7) The area of environmental damage calculated this time only includes the topsoil stripping area and the topsoil cover area of the foundation part.

\subsection{Measurement of environmental analysis of foundation types}

After studying the boundary conditions, three indicators of environmental damage cost, carbon dioxide emissions from construction materials, and carbon dioxide emissions from machinery during construction [1] are selected as environmental protection indicators, and they are quantified and calculated according to certain calculation rules.

\subsubsection{Environmental damage cost}

The cost of environmental damage only considers topsoil stripping and topsoil cover. The area and unit price of topsoil stripping are calculated as follows.

(1) Excavated foundation and single pillar cast-in-place pile: According to single leg $\pi$ (main pillar diameter +2 ) $2 / 4$, a total of 4 tower legs are listed

(2) Board foundation and pile cap cast-in-place pile: Basic size $($ length +6$) \times($ width +6$) \times 4$

(3) Mud sedimentation tank: 50 square meters per leg, $50 \times 4$ per base tower

(4) The peeling thickness is calculated as $30 \mathrm{~cm}$ (plain area)

(5) The unit price of topsoil stripping is 13 yuan/cubic meter

(6) The area covered by the topsoil is the same as the stripped area, and the unit price of the topsoil is 19 yuan/cubic meter

\subsubsection{Carbon dioxide emissions from construction materials}

According to the volume of concrete and steel bars, and based on the $\mathrm{CO} 2$ emission factor obtained from the "Provincial Greenhouse Gas Inventory Compilation Guidelines" (steel CO2 emission factor is $146.41 \mathrm{~kg} / \mathrm{unit}$, concrete $\mathrm{CO} 2$ emission factor is $66.51 \mathrm{~kg} / \mathrm{unit}$ ) [2]. Then calculate the carbon dioxide emissions of construction materials according to the calculation formula of carbon emissions. The calculation formula for carbon emissions is as follows.

$$
\begin{aligned}
\text { Eco2 }=\text { Aelectricity } & \times \text { Felectricity }+\sum_{i=1}^{n} A i \times \mathrm{Ki} \times \mathrm{Ti} \\
& +\sum_{i=1}^{n} M i \times Q i \times m i+\sum_{i=1}^{n} A \text { fuel } \\
& \times \text { Ffuel }
\end{aligned}
$$

Where $\mathrm{A}_{\text {electricity }}$ is the total power consumption of the construction area, living area and office area during the construction and installation phase, $\mathrm{kWh} . \mathrm{F}_{\text {electricity }}$ is the electric power emission factor, $\mathrm{kg} / \mathrm{kWh}$. Ai is the energy consumption value of office vehicles during construction, $\mathrm{kJ} / \mathrm{y} . \mathrm{Ki}$ is the carbon emission factor of the energy consumption value of office vehicles, $\mathrm{kg}$ carbon/ $\mathrm{kJ}$. Ti is the use time of the office vehicle, in years. Mi is the energy contained in the unit building material, $\mathrm{MJ} / \mathrm{kg}$. Qi is the material consumption, $\mathrm{kg}$. $\mathrm{mi}$ is the energy and carbon emission factor corresponding to the material, $\mathrm{kg}$ 
carbon $/ \mathrm{kg}$. $\mathrm{A}_{\text {fuel }}$ is the fuel consumption of mechanical construction equipment, $\mathrm{kg}$. $\mathrm{F}_{\text {fuel }}$ is the carbon emission factor of fuel used by mechanical construction equipment, $\mathrm{kg} / \mathrm{kJ}[3,4]$.

Since the total time and consumption of the single base tower office area are the same, the carbon dioxide emissions of the office area are not considered in this calculation.

\subsubsection{Carbon dioxide emissions from machinery during construction}

According to the number of shifts of each type of machinery during the construction process, and based on the $\mathrm{CO} 2$ emission factor obtained from the "Provincial Greenhouse Gas Inventory Compilation Guide" (gasoline $\mathrm{CO} 2$ emission factor is $2.9251 \mathrm{~kg} / \mathrm{kg}$, diesel $\mathrm{CO} 2$ emission factor is $3.0959 \mathrm{~kg} / \mathrm{kg}$, electricity CO2 emission factor is $0.8843 \mathrm{~kg} / \mathrm{kWh}$ ) [2] and "(2006 Edition) Electric Power Construction Engineering Construction Machinery
Shift Cost Quota" to get the consumption of gasoline, diesel or electric energy of different machinery. Then calculate the mechanical carbon dioxide emissions during the construction process according to the calculation formula of carbon emissions $[4,5]$.

\section{Results and analysis}

According to the methodology above, at first, the results are divided into flat and mountain terrains. Then, under different terrains, the geological conditions are considered separately. After that, the basic force is divided into $600 \mathrm{kN}, 800 \mathrm{kN}, 1000 \mathrm{kN}, 2000 \mathrm{kN}$ and $3000 \mathrm{kN}$. Next, straight line and tensile tower are included. Finally, the economy, environmental damage costs and tons of carbon dioxide emissions from construction materials and machinery during construction under certain conditions are shown in figures.

There are partial results are presented below.

mbody costs(in ten thousands) menvironmental damage costs (in ten thousands) $₫$ carbon dioxide emissions(t)

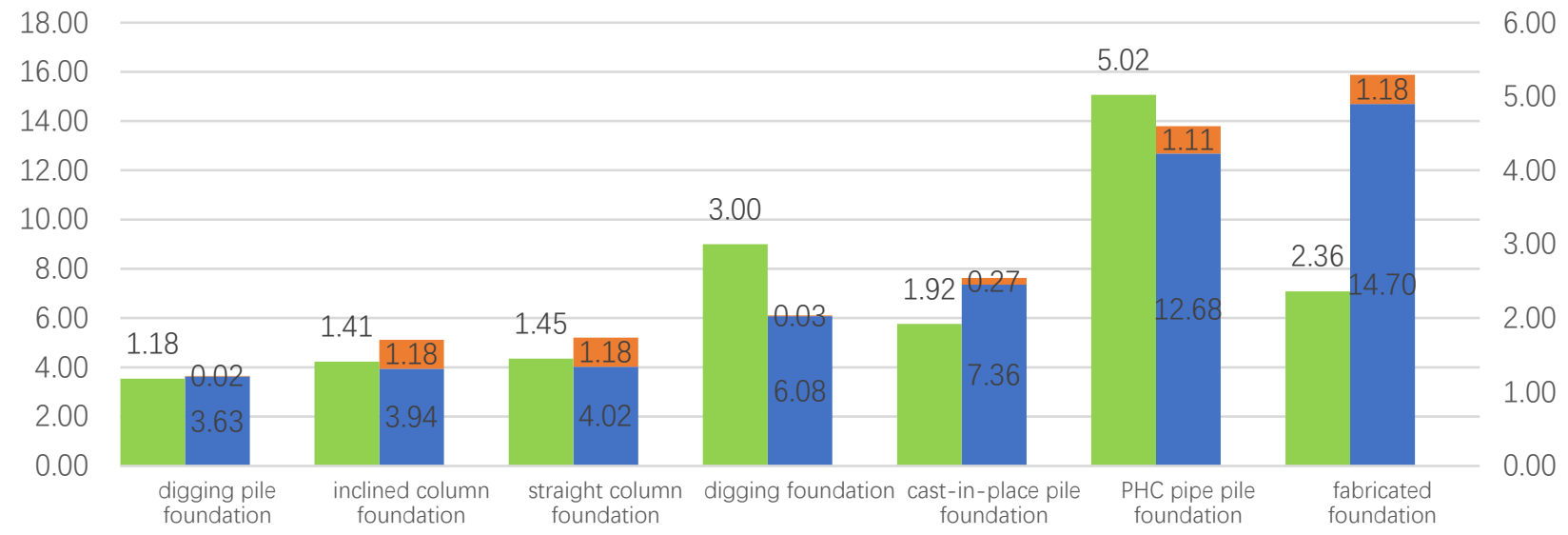

Fig. 1. The linear tower with a foundation force of $600 \mathrm{kN}$ under ordinary soil quality

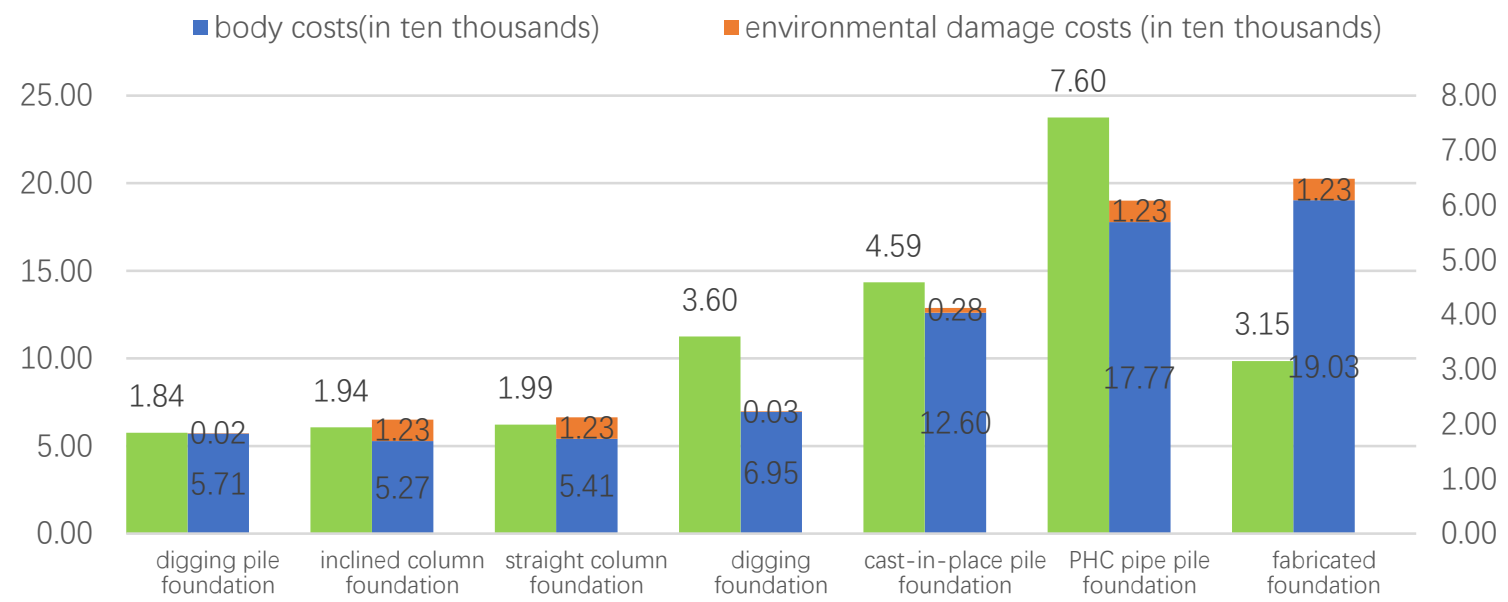

Fig. 2. The tensile tower with a foundation force of $600 \mathrm{kN}$ under ordinary soil quality

Under flat terrain, among all kinds of optional foundations for linear and tensile tower with $600 \mathrm{kN}$ foundation force under ordinary land quality, the lowest total investment of body and environmental damage cost is 36500 yuan and 57300 yuan for excavated pile foundation respectively, while the highest is 158800 yuan and 202600 yuan for fabricated foundation respectively. The lowest total carbon emissions are 1.18 tons and 1.84 tons for digging pile foundation respectively, and the highest is 5.02 tons and 7.60 tons for PHC pipe pile foundation respectively. 


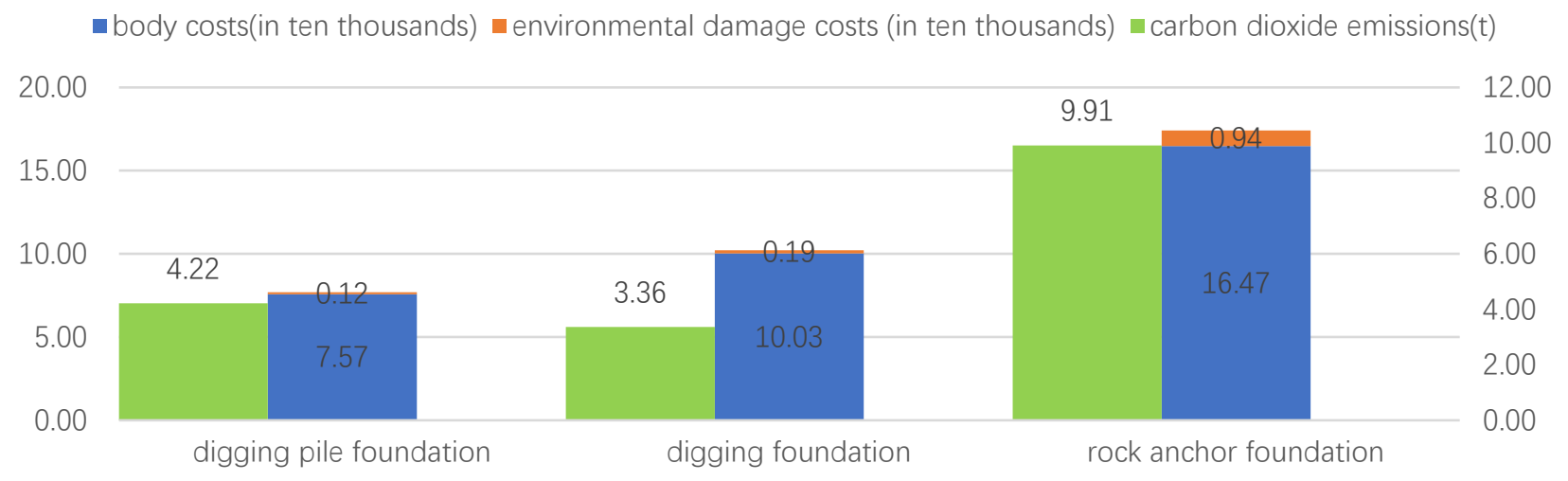

Fig. 3. The linear tower with a foundation force of $1000 \mathrm{kN}$ under rock bolt foundation

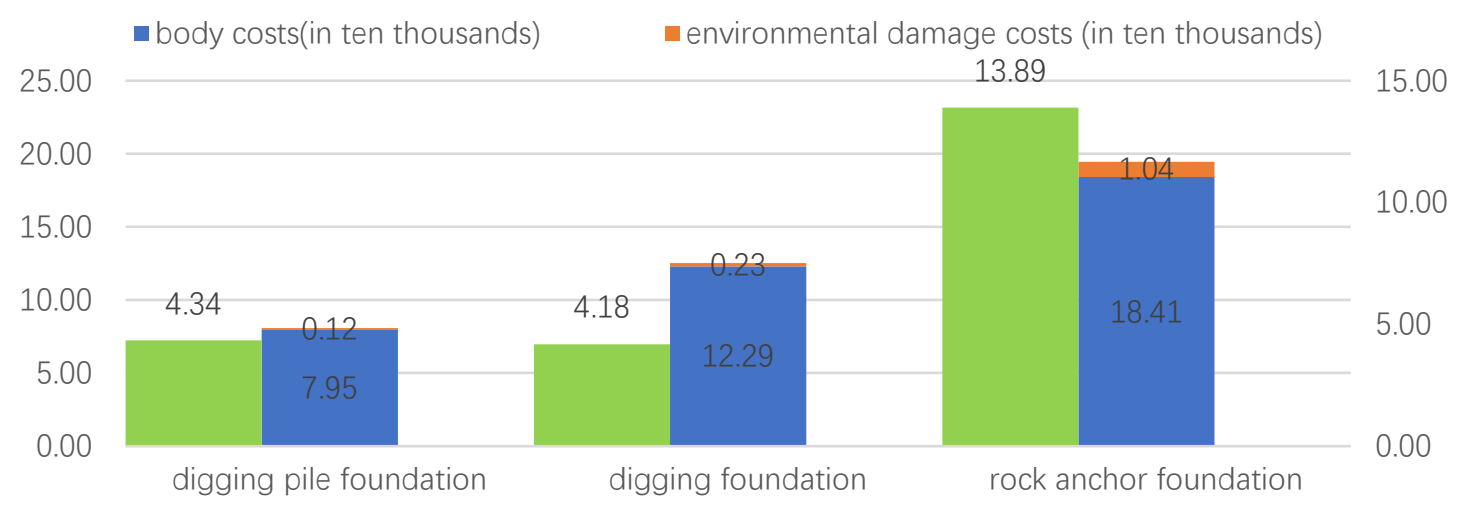

Fig. 4. The tensile tower with a foundation force of $1000 \mathrm{kN}$ under rock bolt foundation

Under mountain terrain, among all kinds of optional foundations for linear tower with $1000 \mathrm{kN}$ foundation force under rock bolt foundation, the lowest total investment of body and environmental damage cost is 76900 yuan for digging pile foundation, while the highest is 174100 yuan for rock anchor foundation. The lowest total carbon emissions are 3.36 tons for digging foundation, and the highest is 9.91 tons for rock anchor foundation. For tensile tower, the lowest total investment of body and environmental damage cost is 80700 yuan for digging pile foundation, while the highest is 194500 yuan for rock anchor foundation. The lowest total carbon emissions are 4.18 tons for digging foundation, and the highest is 13.89 tons for rock anchor foundation.

\section{Conclusion}

The overall trend is that economy and total carbon emissions show a large positive correlation, and there is no large correlation between economy and environmental damage costs. The reason is that the overall investment of various foundations is determined by the superposition of labor, materials, and machinery usage and price. The main influencing factors (energy consumption, emissions, etc.) for evaluating environmental protection are also formed during the construction process that consumes people, materials, and machines. The types of people, materials, and machines consumed by various basic types are also relatively similar. The cost of environmental damage mainly depends on the demand of the foundation type itself for the amount of earth-moving works, and has a small relationship with the cost of the basic type itself. Therefore, the cost of environmental damage mainly depends on the magnitude of the amount of earth-moving works.

\section{Acknowledgments}

I would like to express my gratitude to all the companies and institutions that have provided assistance in field research and data collection, also I would like to express my sincere gratitude to all the experts who have put forward valuable opinions and suggestions. The paper is supported by the Science and Technology Project of State Grid Corporation of China: Research on Optimal Selection of Transmission and Transformation Projects and Intelligent Evaluation of Costs Based on the Design of Wide-area Information Value Mining Links (No. 5200-202156080A-0-0-00).

\section{References}

1. H. Wu, Harbin Institute of Technology (2015)

2. https://wenku.baidu.com/view/7ae95325f111f18583 d05a67.html

3. J. Ji, Modern Industrial Economy and Informationization, 3, 53-55 (2019)

4. Ministry of Electric Power Industry, China Electric Power Press (2006)

5. H. Hua, X.M. Wang, P.Deng, J.Q. He, C.Chen, B.B. Zeng, X.G. Zhang, P. Zhang, Journal of Civil Engineering and Management, 2, 62-67+72 (2014) 